\title{
Allelotype of a Ripening-specific 1-Aminocyclopropane-1-carboxylate Synthase Gene Defines the Rate of Fruit Drop in Apple
}

\author{
Takashi Sato, ${ }^{1}$ Tsuyoshi Kudo, and Tomoko Akada \\ Division of Breeding, Aomori Apple Experimental Station, Botandaira, Kuroishi 036-0332, Japan \\ Yuhya Wakasa, ${ }^{1}$ Minoru Niizeki, and Takeo Harada ${ }^{2}$ \\ Department of Agriculture and Life Science, Hirosaki University, Bunkyo-cho, Hirosaki 036-8561, Japan
}

\begin{abstract}
AdDitional INDEX wORDs. Malus, apple, ethylene, fruit drop, ripening, allelotype
Abstract. The onset of apple [Malus sylvestris (L.) Mill. Var. domestica (Borkh.)Mansf.] fruit maturity is preceded by the production of ethylene, the ripening hormone, which induces fruit ripening. The amount of ethylene produced by the fruit correlates with the level of transcription of the ripening-specific 1-aminocyclopropane-1-carboxylate (ACC) synthase genes. We have found that an allele (MdACS1-2), which contains an inserted retroposon-like sequence at the 5 '-flanking region, is transcribed at a lower level than the wild-type (MdACS1-1).MdACS1-2/2 homozygous fruit produce a lower level of ethylene at the climacteric stage than do the wild type fruit. We have also found that the preharvest drop rates of apple cultivars and strains of MdACS1-2/2 trees have less fruit drop than the MdACS1-1/1 or MdACS11/2 trees. Treatment of the MdACS1-1/2 trees with 1-MCP, an ethylene receptor blocker, further decreased fruit drop. Analysis of commercial apple cultivars for the presence of the MdACS1-2/2 allele may help in the early detection of apple cultivars with a low fruit drop rate.
\end{abstract}

A natural consequence of maturity is abscission, the separation of the fruit from the tree. Thus, preharvest fruit drop results in significant loss of production and potential income. To minimize drop, the growers must treat the apple [Malus sylvestris (L.) Mill. Var. domestica (Borkh.) Mansf.] trees with chemicals (Gardner et al., 1939; Shafer et al., 1995). Government regulations and public perception require growers to reduce the use of chemicals in fruit production. However, there are some apple cultivars that do not require application of drop retarding chemicals because of low rates of fruit abscission.

Fruit abscission is considered to be a similar mechanism as the shedding of leaves and flowers (Sexton and Roberts, 1982). It is the consequence of a series of precisely coordinated events, which lead to the loss of cell-to-cell cohesion. It has been proposed that cell wall breakdown is caused by the action of several hydrolytic enzymes; this has been well documented at both a biochemical (Patterson, 2001; Taylor et al., 1993; Webb et al., 1993) and a molecular level (Brummell et al., 1999; Cho and Cosgrove, 2000; Hong et al., 2000; Mao et al., 2000; Taylor et al., 1994; Tucker et al., 1988). There is convincing evidence that the progress of this coordinated cell separation is regulated by ethylene, and that the timing of abscission is strongly influenced in vivo by ethylene (Beyer, 1975; Jackson and Osborne, 1970).

The amount of ethylene in ripening apple fruit parallels the transcription level of the ripening-specific 1-aminocycloropropane-1-carboxylate (ACC) synthase genes (MdACS1) (Chu, 1988; Harada et al., 2000). An allele (MdACS1-2) of the gene possessing an insertion in the promoter region has very low transcription activity compared with the wild-type allele (MdACS1-1)(Sunako

Received for publication 17 Mar. 2003. Accepted for publication 12 Aug. 2003 We thank J.R. Stow (East Malling, England), N.C. Oraguzie (HortResearch, New Zealand) and G. Hrazdina (Cornell University, Geneva) for their helpful discussion. This work was supported in part by the Ministry of Education, Culture, Sports, Science, and Technology of Japan, and by the Aomori Green Bio Center (M. Suzuki). These experiments were carried out at the Gene Research Center of Hirosaki University.

${ }^{1}$ These authors contributed equally to this work.

2To whom correspondence should be addressed; e-mail tharada@cc.hirosaki-u.ac.jp. et al., 1999). Therefore, MdACS1-2 homozygous cultivars have low levels of ethylene production in the mature fruit (Harada et al., 2000). In this paper, we discuss the allelotype of MdACSI, and its role in fruit ripening and abscission.

\section{Materials and Methods}

Plant materials. Field experiments were conducted at the Aomori Apple Experiment Station throughout 2000 to 2002. In total, 40 apple cultivars and 65 hybrid $\mathrm{F}_{1}$ populations from reciprocal crossings of 'Sansa' and 'Tsugaru' were used for calculating the rate of fruit drop. Strains 94-95 ('Megumi' × 'Toko') and 89-95 ('Megumi' $\times$ 'Golden Delicious') were also used to evaluate the rate of softening. These trees were 8 to 26 years old. They grew on various rootstocks and were managed as in commercial practice except for the application of chemicals to prevent fruit drop.

Determination of MdACS1 alleLIC FORMS. MdACS1 allelic forms were determined using PCR as described by Harada et al. (2000).

FruIt DRoP RATE. Fruit drop was counted twice weekly from $\approx 20$ days before the predicted commercial harvest date that was determined from the change of color of the skin. All fruit remaining on the trees at the harvest date were counted, then cumulative drop per tree was calculated.

Measurement of ETHYLENE AND MATURity indices. Flesh firmness was measured with a hand-held penetrometer (FT-327; Facchini, Italy) fitted with an 11-mm-diameter probe. Two skin discs $(\approx 2.5 \mathrm{~cm}$ in diameter) were removed from opposite sides of each fruit. The penetrometer probe was pressed into the tissue of the cut surface to a depth of 8 to $9 \mathrm{~mm}$ in a single smooth motion. Opposite one-eighth segments from fruit were cut off, and the internal gas was withdrawn from the cortical tissue of one segment submerged in water under vacuum. An aliquant of the gas was measured as described by Harada et al. (2000). The other opposite one-eighth segments from fruit were homogenized and titrated with 0.1 m sodium hydroxide until neutrality ( $\mathrm{pH} 7.0$ ) was attained. Total titratable acidity was calculated as malic acid. 
Table 1. Apple cultivars and their ACS1 allelotype.

\begin{tabular}{|c|c|c|}
\hline Allelotype & Sample no. & Cultivar \\
\hline \multirow[t]{11}{*}{$\overline{A C S 1-1 / 1}$} & 1 & Raritan \\
\hline & 2 & Fujin \\
\hline & 3 & Jerseymac \\
\hline & 4 & Michinoku \\
\hline & 5 & Kagayaki \\
\hline & 6 & McIntosh \\
\hline & 7 & Puritan \\
\hline & 8 & American Summer Pearmain \\
\hline & 9 & Bancroft \\
\hline & 10 & Julyred \\
\hline & 11 & Viking \\
\hline \multirow[t]{19}{*}{$A C S 1-1 / 2$} & 12 & Kanki \\
\hline & 13 & Tangier \\
\hline & 14 & Tsugaru \\
\hline & 15 & Summerred \\
\hline & 16 & Redgold \\
\hline & 17 & Kitaro \\
\hline & 18 & Toko \\
\hline & 19 & Mikiraifu \\
\hline & 20 & Mutsu \\
\hline & 21 & Jonathan \\
\hline & 22 & Starking Delicious \\
\hline & 23 & Goldenmelon \\
\hline & 24 & Kotaro \\
\hline & 25 & $1 / 236$ \\
\hline & 26 & Hokuto \\
\hline & 27 & Orin \\
\hline & 28 & Grannysmith \\
\hline & 29 & Fukutami \\
\hline & 30 & Giant Janet \\
\hline \multirow[t]{10}{*}{$A C S 1-2 / 2$} & 31 & Himekami \\
\hline & 32 & Himekomachi \\
\hline & 33 & Iwakami \\
\hline & 34 & Akane \\
\hline & 35 & Megumi \\
\hline & 36 & Kaori \\
\hline & 37 & Sansa \\
\hline & 38 & Akitagold \\
\hline & 39 & Narihoko \\
\hline & 40 & Fukunishiki \\
\hline
\end{tabular}

Sample number is used in Figs. 1 and 2.

Remaining six-eighths of the fruit were combined in each sample and used for extraction of total RNA (Harada et al. 2000).

MCP TREATMENTS. Two 10-year-old 'Tsugaru' trees were used. On 31 Aug., each fruit (total 93) attached to the tree was enclosed in a transparent polyethylene bag $(250 \times 350 \mathrm{~mm}, 20 \mu \mathrm{m}$ thick $)$ by tying with an elastic band at the pedicel (Parafilm, American National Can Co., Chicago). The future abscission zone was kept out of the bag. Half of the bags contained a microtube containing $2.4 \mathrm{mg}$ of EthylBloc (Rohm and Haas Co., Philadelphia, $\mathrm{Pa}$.). The powder was activated with an injection through the bag of $48 \mu \mathrm{L}$ of water into the microtube, and then the injection hole in the bag was sealed with a vinyl tape. The next morning, the bags were removed. Thus, the fruit were exposed to $\approx 1 \mu \mathrm{L} \cdot \mathrm{L}^{-1} \mathrm{MCP}$ for $15 \mathrm{~h}$ (from 1700 to $0800 \mathrm{HR}$ ).
Preparation of Fruit Pedicel tissue. Thirty fruit form strain '94-95' were harvested on 2 Oct. when about half of the fruit had dropped. Immediately, tips of the pedicels (about $1 \mathrm{~mm}$ ) were sliced off with a razor blade, put into liquid $\mathrm{N}_{2}$ and stored at -85 ${ }^{\circ} \mathrm{C}$ until use. Flesh tissues corresponding these fruit were also prepared from five fruit selected randomly.

NORTHERN BLOT ASSAYS. Total RNA preparation, RNA gel blot analysis, and PCRs were performed as described by Sunako et al. (1999). The probes for northern analysis of ripening-related genes were prepared by PCR using genomic DNA template of the apple cultivar Golden Delicious. The primers and the amplified regions were as follows: ACC synthase (ACS1) 5'-GATGAAAGGTAGCCTGGTCTGA-3' and 5'-TACACTAATCACATTGTATGAATC-3', U89156, 4056-4513; ACC oxidase (MdACO1) 5'-TGAAATTCCAAGCCAAGGAG-3' and 5'-TTCAACTACACAAACAGTGG-3', AF030859, 3558-3780; polygalacturonase $(P G)$, 5'-AAAGGTCATGGAATTGATCAGGCC-3' and 5'-ATGCCCATAATTATGAACCC-3', L27743, 433 -1650; $\beta$-galactosidase $(\beta \mathrm{Gal})$ 5'-ACCACATTCCTCGATCATGG-3' and 5'-TATCTGCTGGATCTGCAGAC-3', L29451, 2243 -2399. Primers and their target regions for RT-PCR were as follows: ACS1 (same as for probe) and ACS5 (5'-CACCGTGTTCAGCCAGCCAAGT-3' and 5'-TCTAAGTGGCTCGAACAAGAGG3', АB034992, 809-1547).

\section{Results}

Fruit DROP RATES OF CULTIVARS. To investigate the relationship between the $M d A C S 1$ allelotypes and fruit abscission, we measured fruit drop rates of 39 cultivars in 2000 and 20 in 2001 (Table 1). These materials were selected with due regard to each ACS1 allelotypes and harvest date. The data from 20 (see Fig .1) cultivars used in both years showed that the drop rate in each cultivar was consistent between years (year-to-year correlation, $r=0.80$ ), indicating that environmental conditions, such as drought or strong winds, which promote abscission, were minimal during harvest in both years (Fig. 1). About half of ACS1-1/1 homozygous (samples 1 to 11 ) and $A C S 1-1 / 2$ heterozygous (samples 12-30) cultivars had drop rates $>50 \%$. On the other hand, all $10 A C S 1-2 / 2$ homozygous cultivars (samples 31 to 40 ) had rates of $<20 \%$. The drop rate of each cultivar in 2001 was plotted against harvest date in Fig. 2. Although most late harvesting cultivars showed very low fruit drop rates, the data show that the low drop rates of $A C S 1-2 / 2$ cultivars were independent of their harvest date.

Fruit drop rate of a F $_{1}$ PROGENy. We measured the fruit drop rates of $\mathrm{F}_{1}$ progeny of reciprocal crosses between 'Tsugaru' (ACS1$1 / 2$ ) and 'Sansa' (ACS1-2/2). This progeny was selected because the harvest dates of both parents are in the first half of September, but

Fig. 1. Rate of cumulative preharvest fruit drop of apple cultivars. Dotted and black bars indicate data in 2000 and 2001, respectively. Cultivar names of each sample number are listed in Table 1.

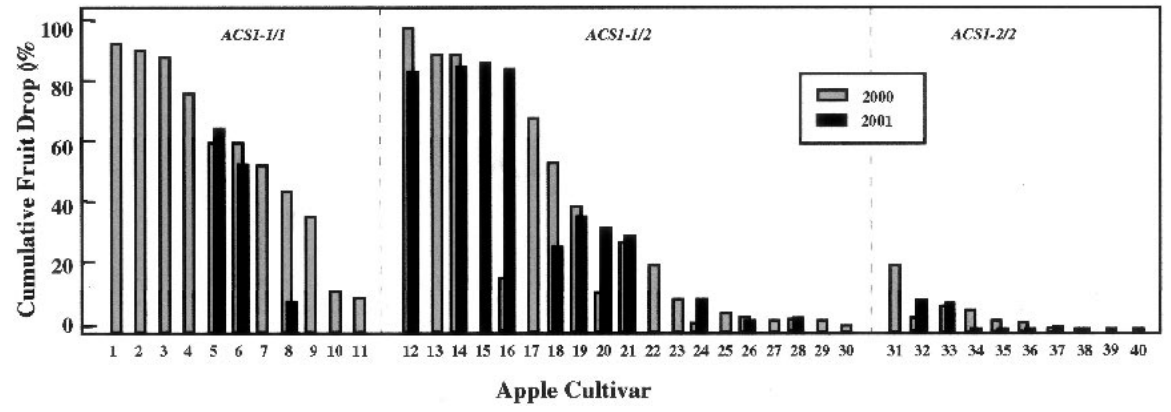




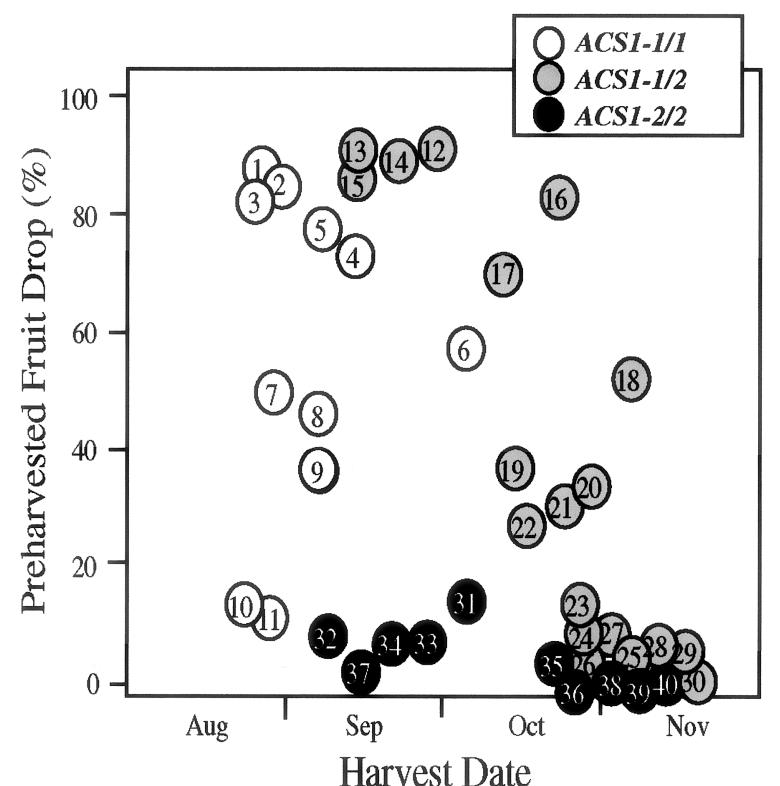

Fig. 2. Relationship between the date of harvest and rate of cumulative fruit drop of 40 apple cultivars. If a cultivar was used in both 2000 and 2001, the higher value was used as the drop rate. The number means cultivar listed in Table 1.

the drop rates are completely different(Figs. 1 and 2, samples 14 and 37). In 2001 and 2002, 28 and 57 trees, respectively, were analyzed. On 17 Sept. 2001, 10 of 12 ACS1-1/2 heterozygous progeny had a drop rate of $>40 \%$, whereas all $A C S 1-2 / 2$ homozygous progeny had a rate of $<40 \%$, and 9 of 16 progeny showed no drop. Fig. 3 shows changes in cumulative percentage drop rates for individual progeny and the average rate of each allelotype in 2002. Almost all $A C S 1-1 / 2$ trees started fruit abscission during late August to early September. On the other hand, with a few of ACS1-2/2 trees fruit abscission started in middle of September, and abscission rate increased with harvest date. Furthermore, half of the trees exhibited $<10 \%$ drop on 28 Sept. As a result, the average drop rate of ACS1$1 / 2$ and $A C S 1-2 / 2$ trees at the end of September was $75.4 \%$ and $14.9 \%$, respectively. These data indicate that the fruit abscission trait segregated according to the allelotype of ACS1.

EFFECT OF MCP TREATMENT TO PREVENT FRUIT DROP. To confirm the involvement of ethylene in fruit abscission, we blocked ethylene signal transduction in the fruit while it was still attached to the tree by using 1-methylcyclopropene (MCP), which acts by inhibiting binding of the ethylene to its receptorbinding site (Serek et al., 1994). A single exposure to $\mathrm{MCP}(1 \mu \mathrm{L}$ $\mathrm{L}^{-1}$ ) dramatically reduced the drop rate of 'Tsugaru' (sample 14). Almost all untreated fruit were dropped by 20 Sept., while $85 \%$ of MCP treated fruit remained on the tree at that time (Fig. 4A). The amount of ethylene in the treated fruit was near background level up to $20 \mathrm{~d}$ after treatment. Northern analysis indicated that none or few transcripts of ripening-related genes were activated in the treated fruit (Fig. 4B). These results indicate that ethylene in the fruit may be responsible for the fruit drop.

No EXPRESSION OF ACS1 IN FRUIT PEDICEL. Figure 5 shows the result of RT-PCR for the mRNA in flesh and pedicel tissue of matured $A C S 1-1 / 2$ fruit. Although ACS5, which has been characterized as wound responsive ACS (Sunako et al., 2000) was detected clearly, no amplification of ACS1 was observed in the mRNA from the pedicel. The results suggest that the ACS1 allelotype affects to the ethylene concentration in matured flesh tissue, and then the ethylene level reflects on the degree of fruit abscission.
NO EFFECT OF ACS1 ALLELOTYPE ON THE FRUIT SOFTENING RATE. To know the relationship between the ACS1 allelotype and fruit softening rate, the fruit attached to different allelotype tree, 94-95 (ACS1-1/2) and 89-95 (ACS1-2/2), were analyzed. These strains were selected because of their similar fruit maturation dates (end of October) and produced enough fruit for the experiments. Tree 94-95 dropped about three-fourths of it fruit by 5 Oct., while tree 89-95 did not drop any fruit at that time. The fruit samples (five each) were harvested and used within one hour of harvest for internal ethylene concentration (IEC) measurements, flesh firmness and titratable acidity. As shown in Fig. 6, nearly identical decreases in firmness and acidity were detected in both genotypes, although great differences were observed in ethylene levels between the two strains, which may explain their ACS1 allelotype. These results indicate that fruit from tree 89-95 exhibited the same softening rate as that from tree 94-95. Northern analysis demonstrated that low ethylene level in fruit of tree 89-95 correlated with the low expression of $A C S 1$. Three ripening-related genes (ACC oxidase, polygalacturonase, and $\beta$-galactosidase) were expressed at a higher level in fruit from tree 89-95, than in fruit from tree 94-95. These results suggest that the ACS1 allelotype responsible for ethylene production in the ripening fruit does not affect the rate of the softening.

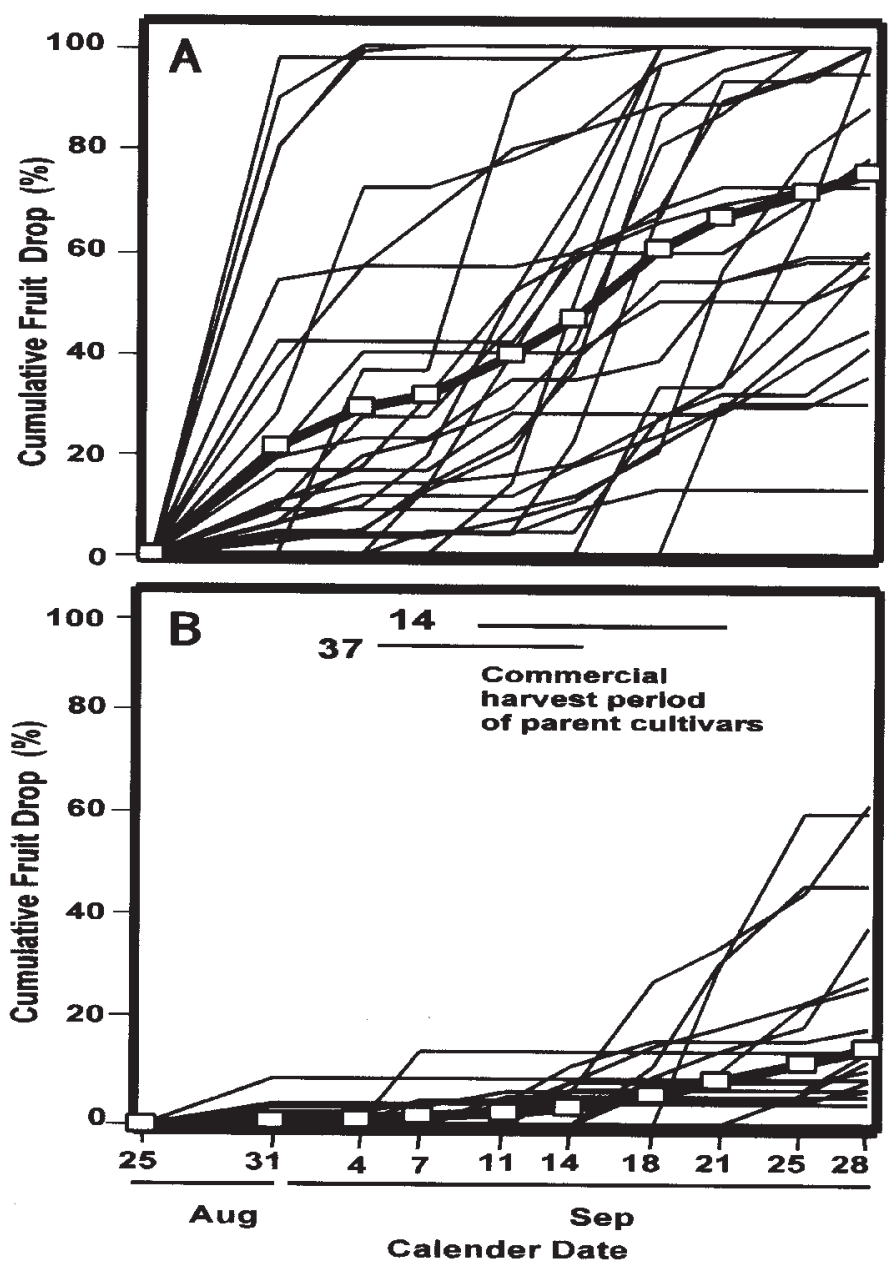

Fig. 3. Cumulative percentage fruit drop of $\mathrm{F}_{1}$ progeny: (A) 30 trees of ACS1-1/2; (B) 27 trees of ACS1-2/2) from reciprocal crosses between 'Sansa' (sample 37) and 'Tsugaru' (sample 14). Thin lines and the thick line indicate each progeny and the average percentage, respectively. The horizontal line indicates the commercial harvest day of parent cultivars. 

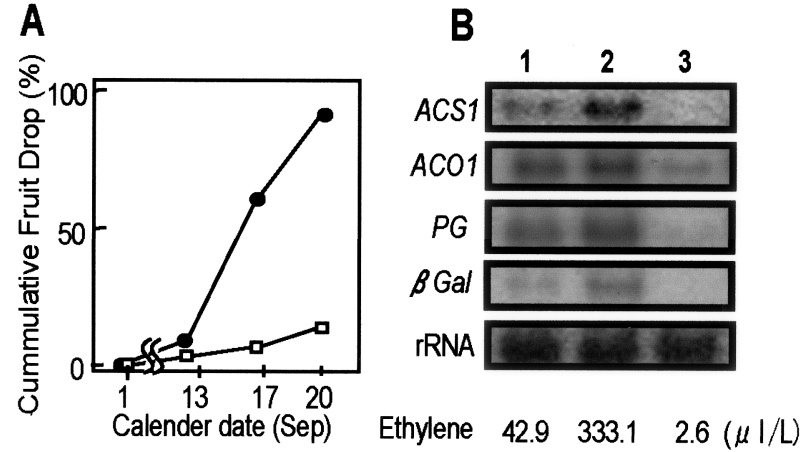

Fig. 4. Effect of 1-MCP treatment on fruit attached to the tree. 'Tsugaru'(sample 14) fruit were treated with 1-MCP on 31 Aug. (A) Cumulative drop rate of control (circles) and MCP-treated fruits (square). (B) RNA gel blot analysis and internal ethylene concentration (IEC, $\mu \mathrm{L} \cdot \mathrm{L}^{-1}$ ) of fruit. Lane 1 , hanging untreated fruit; 2 , dropped untreated fruit; 3, hanging MCP- treated fruit. These fruits were sampled on 24 Sept. Northern blots were performed using $20 \mu \mathrm{g}$ of RNA/lane and probed with ripening-related genes $A C S 1, A C O 1, P G$, and $\beta G a l$ or a loading control, probe rDNA.

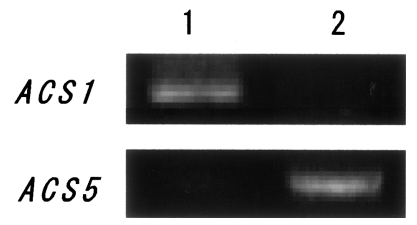

Fig. 5. RT-PCR analysis of ACS1 and ACS5 gene expression in the flesh (lane 1) and the pedicel tissues (lane 2).

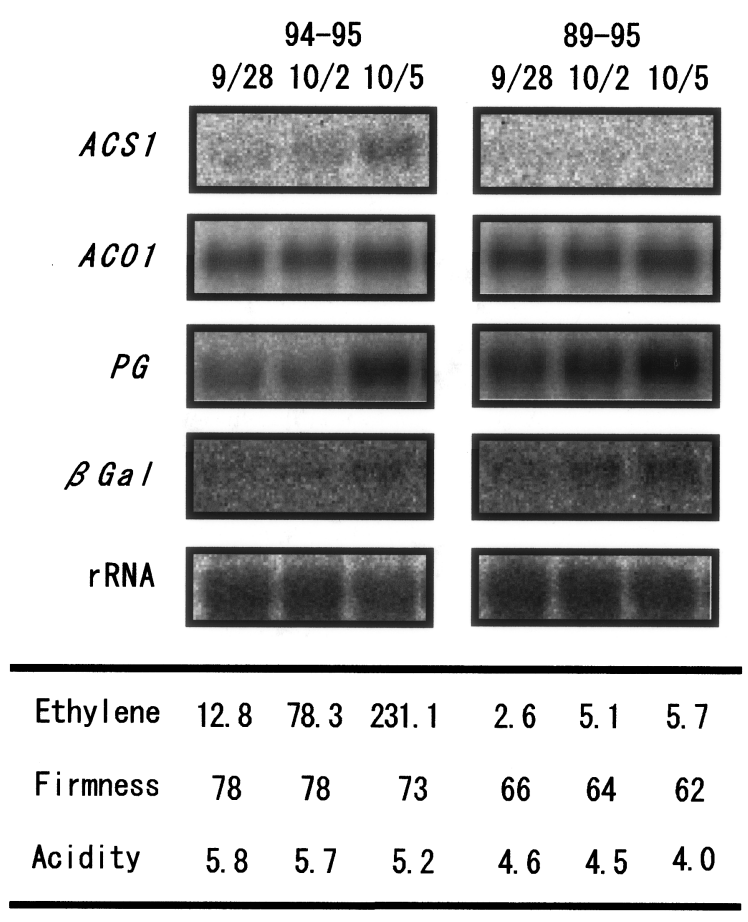

Fig. 6. Softening rate of fruit attached to the tree. Five fruit of strain number 94-95 (ACS1-1/2) and 89-95 (ACS1-2/2) tree were harvested on 28 Sept. and 2 and 5 Oct. Each sample was analyzed for internal ethylene concentration (IEC), flesh firmness and titratable acidity. Cortical tissues were taken for RNA extraction and northern analysis. Northern analysis was performed as in Fig. 4.

\section{Discussion}

Although it is generally believed that apple fruit should abscise at maturity, not all cultivars follow that rule. Furthermore, it is recognized that fruit drop in a cultivar is more prevalent in warmer than colder regions in the same country. Temperature affects not only respiration rate but also, ethylene synthesis rate in ripening apple fruit (Knee et al., 1983a; Lau et al., 1986). Since the average temperature in early November at our experimental orchard was $\approx 10^{\circ} \mathrm{C}$, the low drop rates of late-ripening cultivars of the ACS1-1/2 class, samples 23 to 30 , were probably due to the low ambient temperature. Although early-ripening cultivars seem to be very prone to fruit drop, two ACS1-1/1 cultivars, samples 10 and 11 used in this study, exhibited low fruit drop. An additional complication in early maturing cultivars is that it is difficult to judge when to harvest them because they lack uniformity in maturation. The dates we judged as their harvest times might be earlier than optimum. However, the presence of other possible mechanism(s), by which low fruit drop in the two cultivars is phenotypically expressed, cannot be excluded.

Fruit abscission is considered to be fundamentally similar to the shedding of other plant parts including leaves and parts of the flowers (Bleecker and Patterson, 1997). Flowers of Never ripe ( $\mathrm{Nr}$ ) tomato, a mutant of ethylene receptor, remained attached to the plant indefinitely, and petals remained viable more than four times longer than their normal counterparts (Lanahan et al., 1994). Ethylene's role in accelerating abscission has also been recognized in Arabidopsis ethylene-response mutants etrl, ein2, ein3, and ers2 (Bleecker and Patterson, 1997). The decrease in ethylene synthesis in an ACS antisense Arabidopsis also delayed floral organ abscission (Ecker and Theologis, 1994). The Arabidopsis mutants lack normal ethylene production or its signal transduction in the whole plant. On the other hand, the ACS1-2/2 apple tree had a reduced ethylene production in fruit only, because ACS1 expression has not been detected outside of ripening fruit. Specifically, its expression was undetected in the pedicel of the mature fruit. Although mole numbers of ethylene receptor proteins in apple fruit cells are unknown, the amount of ethylene in ACS1-2/2 is likely to be enough for the receptor to commence ripening. An internal concentration of about 0.1 $\mu \mathrm{L} \cdot \mathrm{L}^{-1}$ has been suggested as the threshold level for the initiation of ripening (Knee et al., 1983b). If the ACS1-2 was a null mutant, the ACS1-2/2 homozygous cultivar would have been eliminated by the breeding system.

The series of plant cell events leading to abscission appears to be primarily controlled by hormonal balance between ethylene and auxin (Sexton and Roberts, 1982). Auxin application effectively delays abscission, and ethylene induces abscission through the regulation of genes for cell wall decomposition enzymes (Hong et al., 2000). To prevent fruit drop, apple growers use synthetic auxins or inhibitors of ethylene synthesis (Gardner et al., 1939; Marini et al., 1988; Shafer et al., 1995; Wang and Diller, 2001). Although these chemicals are sprayed on all parts of the trees, MCP application to fruit only prevented the drop. This result may also suggest that a certain amount of ethylene from fruit could be an initial factor in the induction of abscission zone formation. Therefore, apple fruit abscission may be influenced by the balance between ethylene from the fruit and auxins from the tree. MCPtreated fruit showed a large decrease in the transcription levels of ripening related genes, suggesting that cessation of ethylene action can delay the ripening stage.

Apple breeding is based on selection of superior plants from progenies produced by crossing heterozygous parents. As is the case with other woody perennial plant species, a long period of cultivation of a large number of progenies is needed to breed a new apple variety (Brown, 1975). MdACS1 allelotypes can be easily determined by knowing whether the transposon presences 
or not (Sunako et al., 1999). Excluding seeded offsprings at an early stage would be of great value to the breeding programs. Identification of the MdACS1 allelotype at the seedling stage will allow early and precise pre-selection of the trees that exhibit low preharvest drop.

\section{Literature Cited}

Beyer, Jr., E.M. 1975. The initial effect of ethylene is in the leaf blade. Plant Physiol. 55:322-327.

Bleecker,A.B. and S.E. Patterson. 1997. Last exit: Senescence, abscission, and meristem arrest in Arabidopsis. Plant Cell 9:1169-1179.

Brown, A.G. 1975. Apples, p. 3-37. In: J. Janick and J.N. Moore (eds.). Advances in fruit breeding. Purdue Univ. Press, West Lafayette, Ind.

Brummell, D.A., B.D. Hall, and A.B. Bennet. 1999. Antisense suppression of tomato endo-1,4-glucanase cel1 mRNA accumulation increases the force required to break fruit abscission zones but does not affect fruit softening. Plant Mol. Biol. 40:615-622.

Cho, H-T. and D.J. Cosgrove. 2000. Altered expression of expansin modulates leaf growth and pedicel abscission in Arabidopsis thaliana. Proc. Natl. Acad. Sci. USA 97:9783-9788.

Chu, C.L. 1988. Internal ethylene concentration of McIntosh, Northern Spy, Empire, Mutsu, and Idared apples during the harvest season. J. Amer. Soc. Sci. 113:226-229.

Ecker, J.R. and A. Theologis. 1994. Ethylene: A unique plant signaling molecule, p. 485-521 In: E.M. Meyerowitz and C.R. Somerville (eds.). Arabidopsis. Cold Spring Harbor Press, Plainview, N.Y.

Gardner, F.E., C. P. Marth, and L.P. Batjer. 1939. Spraying with plant growth substances for control of the pre-harvest drop of apples. Proc. Amer. Soc. Hort. Sci. 37:415-428.

Harada, T., T. Sunako, Y. Wakasa, J. Soejima, T. Satoh, and M. Niizeki. 2000. An allele of the 1-aminocyclopropane-1-carboxylate synthase gene (Md-ACS1) accounts for the low level of ethylene production in climacteric fruits of some apple cultivars. Theor. Appl. Genet. 101: 742-746.

Hong, S-B., R. Sexton, and M.L. Tucker. 2000. Analysis of gene promoters for two tomato polygalacturonases expressed in abscission zones and the stigma. Plant Physiol. 123:869-881.

Jackson, M.B. and D.J. Osborne. 1970. Ethylene, the natural regulator of leaf abscission. Nature 225:1019-1022.

Lanahan, M.B., H.C. Ten, J.J. Giovannoni, and M.J. Klee. 1994. The never ripe mutation blocks ethylene perception in tomato. Plant Cell 6:521-530

Lau, O.L., Y. Liu, and S.F. Yang. 1986. Effect of fruit detachment on ethylene biosynthesis and loss of firmness, skin color, and starch in ripening Golden Delicious apple. J. Amer. Soc. Hort. Sci. 111:731-734.

Knee, M., N.E. Looney, S.G.S. Hatfield, and S.M. Smith. 1983a. Initia- tion of rapid ethylene synthesis by apple and pear fruits in relation to storage temperature. J. Expt. Bot. 34:1207-1212.

Knee, M., S.M. Smith, and D.S. Johnson. 1983b. Comparison of methods for estimating the onset of the respiration climacteric in unpicked apples. J. Hort. Sci. 58:521-526.

Mao, L., D. Begum, H-W. Chuang, M.A. Budiman, E.J. Szymkowiak, E.E. Irish, and R. A. Wing. 2000. JINTLESS is a MADS-box gene controlling tomato flower abscission zone development. Nature 406: 910-913.

Marini, R.P., R.E. Byers, D. Sowers, M.E. Marini, and R.W. Young. 1988. Fruit abscission, fruit quality, and residue levels of dichlorprop used to control preharvest drop of apple. HortScience 23:717-719.

Patterson, S.E. 2001. Abscission and dehiscence in Arabidopsis. Plant Physiol. 126:494-500.

Serek, M., E.C. Sisler, and M.S. Reid. 1994. A volatile ethylene inhibitor improves the postharvest life of potted roses. J. Amer. Soc. Hort. Sci. 119:572-577.

Sexton, R. and J.A. Roberts. 1982. Cell biology of abscission. Annu. Rev. Plant. Physiol. 33:133-162.

Shafer, W.E., G. Clarke, J. Hansen, D. Woolard, B.N. Devisetty, and R. Fritts 1995. Practical applications of aminoethoxyvinylglycine. Proc. Plant Growth Regulat. Soc. Amer. 1995:11-15.

Sunako, T., W. Sakuraba, M. Senda, S. Akada, R. Ishikawa, M. Niizeki, and T. Harada. 1999. An allele of the ripening-specific 1-aminocyclopropane-1-carboxylic acid synthase gene (ACS1) in apple fruit with a long storage life. Plant Physiol. 119:1297-1303.

Sunako, T., R. Ishikawa, M. Senda, S. Akada, M. Niizeki, and T. Harada. 2000. MdACS-5A (Accession No. AB034992) and 5B (Accession No. AB034993), Two wound-responsive genes encoding 1-aminocyclopropane-1-carboxylate synthase in apple. (PGR00-030) Plant Physiol. 122:620

Taylor, J.E., S.T.J. Webb, S.A. Coupe, and J.A. Roberts. 1993. Changes in polygalacturonase activity and solubility of polyuronides during ethylene-stimulated leaf abscission in Sambucus nigra. J. Expt. Bot. 44:93-98.

Taylor, J.E., S.A. Coupe, S. Picton, and J.A. Roberts. 1994. Characterization and accumulation pattern of a mRNAencoding an abscission-related B-1,4-glucanase from Sambucus nigra. Plant Mol. Biol. 24:961-964.

Tucker, M.L., R. Sexton, E. del Campillo, and L.N. Lewis. 1988. Characterization of a cDNA clone and regulation of gene expression by ethylene and auxin. Plant Physiol. 88:1257-1262.

Wang, Z., and D.R. Diller. 2001. Aminoethoxyvinylglycine, combined with ethephon, can enhance red color development without over-ripening apples. HortScience 36:328-331.

Webb, S.T.J., J.E. Taylor, S.A. Coupe, G.A. Tucker, and J.A. Roberts. 1993. Purification of $\beta-1$, 4-glucanase from ethylene-treated abscission zones of Sambucus nigra. Plant Cell Environ. 16:329-333. 